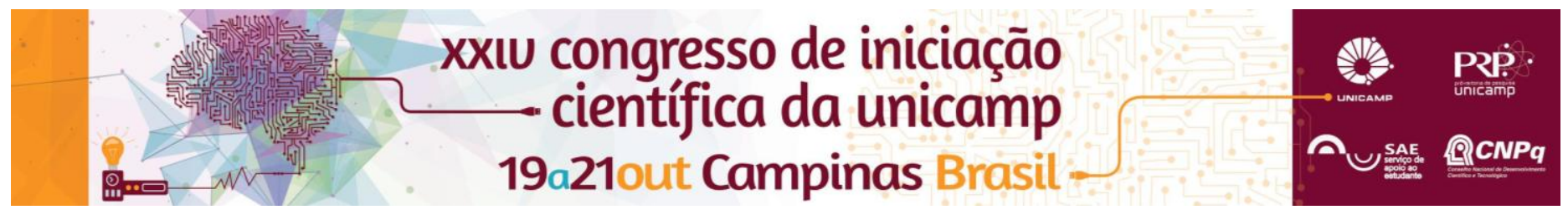

\title{
A Influência da morfologia nasal sobre o ângulo nasolabial
}

\author{
Brenda E Ocaña*, Tais S Rodrigues, Laís G Feliciano, Vania C V Siqueira
}

\section{Resumo}

O ângulo nasolabial indica alterações tanto na inclinação dos incisivos superiores quanto na morfologia nasal e ambos afetam a harmonia facial. Uma das maiores durante o tratamento ortodôntico envolve o nariz e o seu crescimento é um dos principais fatores que influenciam uma harmonia facial satisfatória, especialmente em pacientes que necessitam de retração dos dentes anteriores. A rinoplastia durante ou após o tratamento ortodôntico contribui drasticamente estabelecendo uma harmonia facial, que é um dos objetivos do tratamento ortodôntico. O crescimento nasal ocorre em $100 \%$ dos casos durante o tratamento ortodôntico, mesmo naqueles onde o crescimento facial encerrou-se, o ortodontista poderá empregar uma mecanoterapia conservadora no intuito de minimizar a retração dentária anterior prevenindo danos irreparáveis ao perfil facial.

Palavras-chave: Nariz, perfil facial, ângulo nasolabial

\section{Introdução}

O ângulo nasolabial indica alterações tanto na inclinação dos incisivos superiores quanto na morfologia nasal e ambos afetam a harmonia facial ${ }^{1,2}$. Uma das maiores dificuldades que se apresentam durante 0 tratamento ortodôntico inquestionavelmente envolve 0 nariz e o seu crescimento distorcendo uma face. O seu desenvolvimento é um dos principais fatores que influenciam uma harmonia facial satisfatória, especialmente em pacientes que necessitam de retração dos dentes anteriores ${ }^{1,2}$.

O crescimento nasal ocorre em $100 \%$ dos casos durante o tratamento ortodôntico, mesmo naqueles onde o crescimento facial encerrou-se, o ortodontista poderá empregar uma mecanoterapia conservadora no intuito de minimizar a retração dentária anterior prevenindo danos irreparáveis ao perfil facial. A rinoplastia durante ou após o tratamento ortodôntico contribui drasticamente estabelecendo uma harmonia facial, que é um dos objetivos do tratamento ortodôntico, ${ }^{, 4,5}$.

\section{Resultados e Discussão}

Assim, as alunas do PIBIC EM:

1- receberam informações de como obter informações científicas digitamente;

2-receberam treinamento de leitura, interpretação e redação científicas;

3-selecionaram artigos científicos pertinentes ao tema;

4- realizaram leitura, interpretação e redação dos artigos selecionados;

5- receberam treinamento de mensuração do ângulo nasolabial utilizando desenhos de perfis com diversos tipos de narizes;

6- avaliaram o ângulo nasolabial utilizando fotografias de perfil de artistas veiculadas em revistas;

7- avaliaram 0 ângulo nasolabial utilizando telerradiografias em norma lateral de pacientes entre 09 e 10 anos de idade, do sexo feminino com oclusão normal;

8- receberam treinamento de análise estatística de dados obtidos.

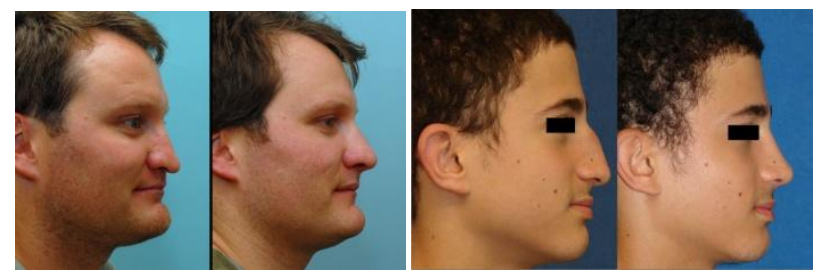

Figura 1. Exemplos de rinoplastias fonte: www.rinoplastia.com.ar

\section{Conclusões}

Os alunos do PIBIC EM desenvolveram atividades que permitiram visualizar a rotina de um pesquisador na área de Odontologia. Como obter as informações publicadas na literatura científica dentro do contexto da pesquisa que está sendo realizada; como realizar leitura e análise científica dos artigos; como obter os dados de sua pesquisa; como analisar os dados utilizando metodologia estatísticas e como obter e analisar os seus resultados

\section{Agradecimentos}

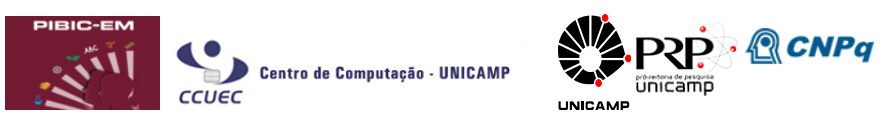

1- Siqueira, VCV. et al. O relacionamento dos ângulos nasolabial e dos incisivos superiores como plano palatino durante a fase do patinho feio. Revista Dental Press de Ortodontia e Ortopedia Facial. 2003,8,31-42.

2- SIQUEIRA, VC.V. Avaliação do ângulo nasolabial após o tratamento ortodôntico com e sem extração dos primeiros pré-molares. Revista Dental Press de Ortodontia e Ortopedia Facial. 2008,13 (6): 51-58.

3-CLEMENTS, B. S. Nasal imbalance and the orthodontic patient. Am. J. Orthod.Dentofacial Orthop.1969, 55(3): 244-64.

4-CLEMENTS, B. S. Nasal imbalance and the orthodontic patient. Am. J. Orthod. Dentofacial Orthop. 1969, 55(4): 329-52.

5-CLEMENTS, B. S. Nasal imbalance and the orthodontic patient. Am. J. Orthod. Dentofacial Orthop. 1969, 55(5):477-97. 